\title{
Pengaruh Kompensasi Dan Kepuasan Kerja Terhadap Kinerja Karyawan Pada PT. Mitra Agung Persada Di Jakarta
}

\author{
${ }^{1} N$. Lilis Suryani, ${ }^{2}$ Hastono \\ Dosen Fakultas Ekonomi Universitas Pamulang \\ Email : ${ }^{1}$ dosen000437@unpam.ac.id, ${ }^{2}$ dosen00340@unpam.ac.id
}

\begin{abstract}
ABSTRAK
Penelitian ini bertujuan untuk mengetahui pengaruh kompensasi dan kepuasan kerja terhadap kinerja karyawan pada PT. Mitra Agung Persada di Jakarta.

Metode yang digunakan adalah explanatory research dengan sampel sebanyak 73 responden. Teknik analisis menggunakan analisis statistik dengan pengujian regresi, korelasi, determinasi dan uji hipotesis.

Hasil penelitian ini kompensasi berpengaruh signifikan terhadap kinerja karyawan sebesar 37,8\%, uji hipotesis diperoleh signifikansi $0,000<0,05$. Kepuasan kerja berpengaruh signifikan terhadap kinerja karyawan sebesar 39,6\%, uji hipotesis diperoleh signifikansi $0,000<0,05$. Kompensasi dan kepuasan kerja secara simultan berpengaruh signifikan terhadap kinerja karyawan sebesar 50,6\%, uji hipotesis diperoleh signifikansi $0,000<0,05$.
\end{abstract}

Kata Kunci: Kompensasi, Kepuasan kerja, Kinerja Karyawan 


\section{PENDAHULUAN}

\section{Latar Belakang Masalah}

Dalam menghadapi dunia usaha, dimana persaingan semakin ketat, perusahaan harus mempunyai strategi agar dapat bertahan dan bersaing dalam dunia bisnis. Perkembangan jaman yang semakin berkembang dan maju menuntut organisasi agar dapat melaksanakan tujuan organisasi dengan efektif. Oleh karena itu peran sumber daya manusia sangat di butuhkan dalam proses kelangsungan proses organisasi itu sendiri. Sumber daya manusia merupakan aset bagi perusahaan, jika perusahaan memiliki sumber daya manusia yang baik maka akan membantu menggerakan sumber daya yang lain yang dapat membuat perusahaan maju dan berkembang sehinga dapat bertahan ditengah persaingan bisnis yang ketat. Dengan demikian penting mengelola sumber daya manusia agar terwujud tujuan organisasi secara efektif.

Kompensasi adalah seluruh imbalan yang diterima karyawan atas hasil kerja karyawan tersebut pada organisasi. Kompensasi bisa berupa fisik maupun non fisik dan harus dihitung dan diberikan kepada karyawan sesuai dengan pengorbanan yang telah diberikannya kepada organisasi / perusahaan tempat ia bekerja". Menurut Rivai (2016) "kompensasi adalah merupakan sesuatu yang diterima karyawan sebagai pengganti kontribusi jasa mereka pada perusahaan, pemberian kompensasi merupakan salah satu pelaksanaan fungsi
MSDM yang berhubungan dengan semua jenis penghargaan individual sebagi pertukaran dalam melakukan tugas ke ogranisasian". Hal tersebut juga selaras dengan pendapat Dessler (2005) menyatakan bahwa kompensasi karyawan merujuk pada semua bentuk bayaran atau imbalan bagi karyawan dan berasal dari pekerjaan mereka.

Dari keinginan untuk memenuhi kebutuhan-kebutuhan dasar, sampai kepada usaha untuk memenuhi kebutuhan yang lebih tinggi. Oleh karena itu jika karyawan mendapatkan kompensasi yang layak dan dapat memenuhi kebutuhannya, maka karyawan akan merasa puas dalam bekerja dan Kinerja Karyawan pun dapat berkurang. Semakin besar kompensasi yang diterima oleh karyawan maka semakin besar pula kepuasan kerja yang dirasakan oleh karyawan dan jika kepuasan kerja yang karyawan rasakan semakin besar maka semakin kecil Kinerja Karyawan yang akan terjadi pada perusahaan. Kompensasi yang diberikan bukan hanya soal gaji yang diberikan, namun dari segi pemberian insentif, Asuransi kesehatan, jaminan sosial bahkan jatah cuti pun merupakan bagian dari kompensasi yang harus diberikan oleh perusahaan kepada karyawan, jika semua itu dapat terpenuhi oleh perusahaan maka kepuasan kerja pun akan semakin meningkat dan jelas akan mengurangi tingkat intensitas turnover yang terjadi selama ini.

Kepuasan kerja adalah tingkat kesenangan yang dirasakan 
seseorang atas peranan atau pekerjaannya dalam organisasi. Tingkat rasa puas individu bahwa mereka mendapat imbalan yang setimpal dari bermacam-macam aspek situasi pekerjaan dari organisasi tempat mereka bekerja. Jadi kepuasan kerja menyangkut psikologis individu didalam organisasi, yang diakibatkan oleh keadaan yang ia rasakan dari lingkungannya.

Menurut Handoko (2000) mengemukakan bahwa kepuasan kerja (Job Satisfaction) adalah keadaan emosional yang menyenangkan atau tidak menyenangkan dengan para karyawan memandang pekerjaan mereka. Waktu/lama penyelesaian merupakan pencerminan perasaan seseorang terhadap pekerjaannya. Hal ini dapat dilihat dari sikap positif karyawan terhadap pekerjaan dan segala sesuatu di lingkungannya.

Salah satu penyebab karyawan melakukan turnover adalah karyawan merasa tidak puas bekerja pada perusahaan, kepuasan kerja haruslah diciptakan perusahaan dan bisa dirasakan oleh karyawan, kepuasan kerja karyawan dapat tercipta apabila keinginan-keinginan karyawan dapat terpenuhi, masalah lingkungan kerja yang baik, sistem kompensasi yang baik, pemberian motivasi, gaya kepemimpinan merupakan beberapa hal yang dapat menciptakan kepuasan kerja karyawan.

Kinerja pada umumnya diartikan sebagai kesuksesan seseorang dalam melaksanakan suatu pekerjaan. Kinerja karyawan merupakan hasil kerja yang dicapai seseorang dalam melaksanakan tugas-tugas yang dibebankan kepadanya untuk mencapai target kerja. Karyawan dapat bekerja dengan baik bila memiliki kinerja yang tinggi sehingga dapat menghasilkan kerja yang baik. Kinerja karyawan merupakan salah satu faktor penentu keberhasilan perusahaan atau organisasi dalam mencapai tujuannya. Untuk itu kinerja dari para karyawan harus mendapat perhatian dari para pimpinan perusahaan, sebab menurunnya kinerja dari karyawan dapat mempengaruhi kinerja perusahaan secara keseluruhan.

Berdasarkan uraian pada latar belakang di atas, maka penulis meneliti dengan judul "Pengaruh kompensasi dan kepuasan kerja terhadap kinerja karyawan pada PT. Mitra Agung Persada di Jakarta".

\section{Rumusan Masalah}

a. Adakah pengaruh secara parsial antara kompensasi terhadap kinerja karyawan pada PT. Mitra Agung Persada di Jakarta ?.

b. Adakah pengaruh secara parsial antara kepuasan kerja terhadap kinerja karyawan pada PT. Mitra Agung Persada di Jakarta ?.

c. Adakah pengaruh secara simultan antara kompensasi dan kepuasan kerja terhadap kinerja karyawan pada PT. Mitra Agung Persada di Jakarta?.

\section{Tujuan Penelitian}

a. Untuk mengetahui pengaruh secara parsial antara kompensasi terhadap kinerja 
karyawan pada PT. Mitra Agung Persada di Jakarta?.

b. Untuk mengetahui pengaruh secara parsial antara kepuasan kerja terhadap kinerja karyawan pada PT. Mitra Agung Persada di Jakarta?.

c. Untuk mengetahui pengaruh secara simultan antara kompensasi dan kepuasan kerja terhadap kinerja karyawan pada PT. Mitra Agung Persada di Jakarta?

\section{TINJAUAN PUSTAKA}

\section{Kompensasi}

Yang dimaksud dengan kompensasi dalam penelitian ini adalah apa yang diterima karyawan sebagai ganti kontribusi mereka kepada perusahaan. Pada umumnya karyawan bekerja juga ingin memeperoleh uang untuk memenuhi kebutuhan hidupnya. Untuk itulah seorang karyawan mulai menghargai kerja keras dan semakin menunjukan loyalitas terhadap perusahaan agar perusahaan memberikan penghargaan terhadap prestasi kerja karyawan yaitu dengan memberikan kompensasi. Kompensasi menurut Husein Umar adalah segala sesuatu yang diterima oleh pegawai, baik itu berupa gaji, upah, insentif, asuransi dan lain-lain, yang sejenis yang dibayar langsung perusahaan (Husein Umar 2007:16).

\section{Kepuasan Kerja}

Yang dimaksud kepuasan kerja adalah sebagai sikap umum seorang individu terhadap pekerjaannya, kepuasan kerja yang tinggi menunjukan sikap positif terhadap pekerjaan itu, sebaliknya seorang yang tidak puas dengan pekerjaannya menunjukan sikap yang negative terhadap pekerjaan itu dan merupakan sikap karyawan yang berkaitan dengan keadaan psikologisnya.

Kepuasan Kerja adalah Evaluasi yang menggambarkan seseorang atas perasaan sikapnya senang atau tidak senang, puas atau tidak puas dalam bekerja (Rivai dan Sagala 2010:860).

\section{Kinerja Karyawan}

Kinerja Karyawan disini mengacu pada hasil kerja baik secara kualitas maupun kuantitas yang dicapai oleh seseorang dalam melaksanakan tugas sesuai tanggung jawab yang diberikan. Kinerja adalah hasil pekerjaan yang dicapai karyawan berdasarkan persyaratanpersyaratan pekerjaan (Bangun 2012:231)

\section{METODE PENELITIAN}

\section{Populasi}

Populasi dalam penelitian ini berjumlah 73 responden PT. Mitra Agung Persada di Jakarta

\section{Sampel}

Teknik pengambilan sampling dalam penelitian ini adalah samplel jenuh, dimana semua anggota populasi dijasikan sebagai sampel. Dengan demikian sampel dalam penelitian ini berjumlah 73 responden.

\section{Jenis Penelitian}

Jenis penelitian yang dipakai adalah asosiatif, dimana tujuannya adalah untuk mengetahui mencari keterhubungan antara. 
4. Metode Analisis Data

Dalam menganalisis data digunakan uji instrumen, uji asumsi klasik, regresi, koefisien determinasi dan uji hipotesis.

\section{HASIL PENELITIAN}

Tabel 1. Hasil Analisis Descriptive Statistics

\section{Descriptive Statistics}

\begin{tabular}{l|r|r|r|r|r} 
& N & Minimum & Maximum & Mean & Std. Deviation \\
\hline Kompensasi (X1) & 73 & 32 & 47 & 38.33 & 3.927 \\
\hline Kepuasan Kerja (X2) & 73 & 30 & 49 & 38.77 & 4.486 \\
\hline Kinerja Karyawan (Y) & 73 & 31 & 47 & 39.34 & 3.656 \\
\hline Valid N (listwise) & 73 & & & & \\
\hline
\end{tabular}

Kompensasi diperoleh varians minimum sebesar 32 dan varians maximum 47 dengan mean score sebesar 3,83 dengan standar deviasi 3,927.

Kepuasan kerja diperoleh varians minimum sebesar 30 dan varians maximum 49 dengan mean score sebesar 3,87 dengan standar deviasi 4,486.

Kinerja karyawan diperoleh varians minimum sebesar 31 dan varians maximum 47 dengan mean score sebesar 3,93 dengan standar deviasi 3,656.

\section{Analisis Verifikatif.}

Pada analisis ini dimaksudkan untuk mengetahui pengaruh variabel independen terhadap variabel dependen. Adapun hasil pengujian sebagai berikut:

\section{a. Analisis Regresi Linier Berganda}

Uji regresi ini dimaksudkan untuk mengetahui perubahan variabel dependen jika variabel independen mengalami perubahan. Adapun hasil pengujiannya sebagai berikut:

Tabel 2. Hasil Pengujian Regresi Liner Berganda Coefficients $^{\mathrm{a}}$ Unstandardized Coefficients

\begin{tabular}{|c|c|c|c|c|c|}
\hline$\frac{\text { Model }}{1}$ & B & Std. Error & Beta & $\mathrm{t}$ & Sig. \\
\hline $1 \quad$ (Constant) & 12.025 & 3.265 & & 3.683 & .000 \\
\hline Kompensasi (X1) & .365 & .092 & .392 & 3.964 & .000 \\
\hline Kepuasan Kerja (X2) & .344 & .081 & .422 & 4.262 & .000 \\
\hline
\end{tabular}

a. Dependent Variable: Kinerja Karyawan (Y)

Berdasarkan hasil pengujian pada tabel di atas, diperoleh persamaan regresi $\mathrm{Y}=12,025+$ $0,365 \mathrm{X} 1+0,344 \mathrm{X} 2 . \quad$ Dari persamaan tersebut dijelaskan sebagai berikut: a) Konstanta sebesar 12,025 diartikan jika kompensasi dan kepuasan kerja tidak ada, maka telah terdapat nilai kinerja karyawan sebesar 12,025 point. 
b) Koefisien regresi kompensasi sebesar 0,365, angka ini positif artinya setiap ada peningkatan kompensasi sebesar 0,365 maka kinerja karyawan juga akan mengalami peningkatan sebesar 0,365 point.

c) Koefisien regresi kepuasan kerja sebesar 0,344, angka ini positif artinya setiap ada peningkatan kepuasan kerja sebesar 0,344 maka kinerja karyawan juga akan mengalami peningkatan sebesar 0,344 point.

\section{b. Analisis Koefisien Korelasi}

Analisis koefisien

korelasi dimaksudkan untuk mengetahui tingkt kekuatan hubungan dari variabel independen terhadap variabel dependen baik secara parsial maupun simultan. Adapun hasil pengujian sebagai berikut:

Tabel 3. Hasil Pengujian Koefisien Korelasi Kompensasi Terhadap Kinerja Karyawan.

Correlations $^{\mathrm{b}}$

\begin{tabular}{ll|r|r} 
& & $\begin{array}{c}\text { Kompensasi } \\
(\mathrm{X} 1)\end{array}$ & $\begin{array}{r}\text { Kinerja Karyawan } \\
(Y)\end{array}$ \\
\hline Kompensasi (X1) & Pearson Correlation & 1 & $.615^{* *}$ \\
\cline { 2 - 4 } & Sig. (2-tailed) & & .000 \\
\hline Kinerja Karyawan (Y) & Pearson Correlation & $.615^{* *}$ & 1 \\
\cline { 2 - 4 } & Sig. (2-tailed) & .000 & \\
\hline
\end{tabular}

**. Correlation is significant at the 0.01 level (2-tailed).

b. Listwise $\mathrm{N}=73$

$\begin{array}{lrl}\text { Berdasarkan } & \text { hasil } & \text { kompensasi memiliki hubungan } \\ \text { pengujian diperoleh } & \text { nilai } & \text { yang kuat terhadap kinerja } \\ \text { korelasi sebesar } 0,615 \text { artinya } & \text { karyawan. }\end{array}$

Tabel 4. Hasil Pengujian Koefisien Korelasi Kepuasan Kerja Terhadap Kinerja Karyawan

Correlations $^{\mathrm{b}}$

\begin{tabular}{llr|r} 
& \multicolumn{1}{c}{$\begin{array}{c}\text { Kepuasan } \\
\text { Kerja (X2) }\end{array}$} & \multicolumn{1}{c}{$\begin{array}{c}\text { Kinerja } \\
\text { Karyawan (Y) }\end{array}$} \\
\hline Kepuasan Kerja (X2) & $\begin{array}{l}\text { Pearson } \\
\text { Correlation }\end{array}$ & 1 & $.629^{* *}$ \\
& Sig. (2-tailed) & & .000 \\
\hline Kinerja Karyawan (Y) & $\begin{array}{l}\text { Pearson } \\
\text { Correlation }\end{array}$ & $.629^{* *}$ & 1 \\
\cline { 2 - 3 } & Sig. (2-tailed) & .000 & \\
\hline
\end{tabular}

**. Correlation is significant at the 0.01 level (2-tailed).

b. Listwise $\mathrm{N}=73$

Berdasarkan hasil pengujian diperoleh nilai korelasi sebesar 0,629 artinya kepuasan kerja memiliki hubungan yang kuat terhadap kinerja karyawan. 
Tabel 5. Hasil Pengujian Koefisien

Korelasi Kompensasi dan

Kepuasan Kerja secara simultan

Terhadap Kinerja Karyawan Model Summary

Std.

Error of

\begin{tabular}{rr|c|r|r}
$\begin{array}{l}\text { Mode } \\
1\end{array}$ & $\mathrm{R}$ & $\begin{array}{c}\text { Squar } \\
\mathrm{e}\end{array}$ & $\begin{array}{c}\text { Adjuste } \\
\mathrm{d} \mathrm{R} \\
\text { Square }\end{array}$ & $\begin{array}{c}\text { Estimat } \\
\mathrm{e}\end{array}$ \\
\hline 1 & .712 & .506 & .492 & 2.605 \\
$\mathrm{a}$ & & & \\
\hline
\end{tabular}

a. Predictors: (Constant), Kepuasan

Kerja (X2), Kompensasi (X1)

Berdasarkan hasil pengujian diperoleh nilai korelasi sebesar 0,712 artinya kompensasi dan kepuasan kerja secara simultan memiliki hubungan yang kuat terhadap kinerja karyawan.

c. Analisis

Koefisien

Determinasi

Analisis koefisien

determinasi dimaksudkan untuk mengetahui besarnya persentase pengaruh dari variabel independen terhadap variabel dependen baik secara parsial maupun simultan. Adapun hasil pengujian sebagai berikut:

Tabel 6. Hasil Pengujian Koefisien

Determinasi Kompensasi

Terhadap Kinerja Karyawan Model Summary

\begin{tabular}{|c|c|c|c|c|}
\hline $\begin{array}{l}\text { Mode } \\
1\end{array}$ & $\mathrm{R}$ & $\begin{array}{c}\mathrm{R} \\
\text { Squar } \\
\mathrm{e}\end{array}$ & $\begin{array}{c}\text { Adjuste } \\
\text { d R } \\
\text { Square }\end{array}$ & $\begin{array}{l}\text { Std. } \\
\text { Error of } \\
\text { the } \\
\text { Estimat } \\
\mathrm{e}\end{array}$ \\
\hline 1 & .615 & .378 & .370 & 2.903 \\
\hline
\end{tabular}

a. Predictors: (Constant), Kompensasi (X1)

\begin{tabular}{lcr}
\multicolumn{2}{c}{ Berdasarkan } & hasil \\
pengujian & diperoleh & nilai \\
determinasi & sebesar & 0,378
\end{tabular}

artinya kompensasi memiliki kontribusi pengaruh sebesar $37,8 \%$ terhadap kinerja karyawan.

Tabel 7. Hasil Pengujian Koefisien

Determinasi Kepuasan Kerja

Terhadap Kinerja Karyawan Model Summary

Std. $\mathrm{R}$ Adjuste $\begin{gathered}\text { Error of } \\ \text { the }\end{gathered}$

Mode $\mathrm{Squar} \mathrm{d} \mathrm{R}$ Estimat

\begin{tabular}{ll|l|r|c}
1 & $\mathrm{R}$ & $\mathrm{e}$ & Square & $\mathrm{e}$ \\
\hline 1 & .629 & .396 & .387 & 2.862
\end{tabular}

a. Predictors: (Constant), Kepuasan Kerja (X2)

Berdasarkan hasil pengujian diperoleh nilai determinasi sebesar 0,396 artinya kepuasan kerja memiliki kontribusi pengaruh sebesar $39,6 \%$ terhadap kinerja karyawan.

Tabel 8. Hasil Pengujian Koefisien Determinasi Kompensasi dan Kepuasan Kerja Terhadap Kinerja Karyawan Model Summary

\begin{tabular}{|c|c|c|c|c|}
\hline $\begin{array}{l}\text { Mode } \\
1\end{array}$ & $\mathrm{R}$ & $\begin{array}{c}\mathrm{R} \\
\text { Squar } \\
\mathrm{e}\end{array}$ & $\begin{array}{c}\text { Adjuste } \\
\text { d R } \\
\text { Square }\end{array}$ & $\begin{array}{c}\text { Std. } \\
\text { Error of } \\
\text { the } \\
\text { Estimat } \\
\mathrm{e}\end{array}$ \\
\hline 1 & $\begin{array}{r}.712 \\
\mathrm{a}\end{array}$ & .506 & .492 & 2.605 \\
\hline
\end{tabular}

a. Predictors: (Constant), Kepuasan

Kerja (X2), Kompensasi (X1)

Berdasarkan hasil pengujian diperoleh nilai determinasi sebesar 0,506 artinya kompensasi dan kepuasan kerja secara simultan memiliki kontribusi pengaruh sebesar 50,6\% terhadap kinerja karyawan, sedangkan sisanya sebesar 49,4\% dipengaruhi faktor lain.. 
d. Uji Hipotesis

Uji hipotesis Parsial (Uji t)

Pengujian hipotesis dengan uji t digunakan untuk mengetahui hipotesis parsial mana yang diterima.

Hipotesis pertama: Terdapat pengaruh yang signifikan antara kompensasi terhadap kinerja karyawan.

Tabel 9. Hasil Uji Hipotesis

Kompensasi Terhadap Kinerja

Karyawan

Coefficients $^{\mathrm{a}}$

\begin{tabular}{|c|c|c|c|c|c|}
\hline Model & $\begin{array}{r}\text { Unst } \\
\text { di } \\
\text { Coef }\end{array}$ & $\begin{array}{l}\text { andar } \\
\text { ed } \\
\text { ficien } \\
\text { s } \\
\text { Std. } \\
\text { Erro } \\
\quad \text { r }\end{array}$ & $\begin{array}{c}\text { Standar } \\
\text { dized } \\
\text { Coeffic } \\
\text { ients } \\
\text { Beta }\end{array}$ & $\mathrm{t}$ & $\mathrm{Si}$ \\
\hline $\begin{array}{l}1 \text { (Const } \\
\text { ant) }\end{array}$ & $\begin{array}{r}17 . \\
391\end{array}$ & $\begin{array}{r}3.35 \\
7\end{array}$ & & $\begin{array}{r}5.1 \\
81\end{array}$ & .0 \\
\hline $\begin{array}{l}\text { Kompe } \\
\text { nsasi } \\
\text { (X1) }\end{array}$ & $\begin{array}{r}.57 \\
3\end{array}$ & .087 & .615 & $\begin{array}{r}6.5 \\
73\end{array}$ & .0 \\
\hline
\end{tabular}

a. Dependent Variable: Kinerja

Karyawan (Y)

Berdasarkan hasil pengujian pada tabel di atas, diperoleh nilai $\mathrm{t}$ hitung $>\mathrm{t}$ tabel atau $(6,573>1,994)$, dengan demikian hipotesis pertama yang diajukan bahwa terdapat pengaruh yang signifikan atara kompensasi terhadap kinerja karyawan diterima.

\section{Tabel 10. Hasil Uji Hipotesis \\ Kepuasan Kerja Terhadap \\ Kinerja Karyawan \\ Coefficients $^{\mathrm{a}}$}

Unstandar Standar dized dized

Coefficien Coeffici

\begin{tabular}{|c|c|c|c|c|c|}
\hline Model & 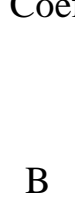 & $\begin{array}{l}\text { Std. } \\
\text { Erro } \\
r\end{array}$ & ents & $\mathrm{t}$ & \\
\hline $\begin{array}{c}1 \text { (Cons } \\
\text { tant) }\end{array}$ & $\begin{array}{r}19 . \\
469 \\
\end{array}$ & $\begin{array}{r}2.93 \\
4 \\
\end{array}$ & & $\begin{array}{r}6.6 \\
36\end{array}$ & \\
\hline $\begin{array}{l}\text { Kepua } \\
\text { san } \\
\text { Kerja } \\
\text { (X2) }\end{array}$ & $\begin{array}{r}.51 \\
3\end{array}$ & .075 & .629 & $\begin{array}{r}6.8 \\
18\end{array}$ & \\
\hline
\end{tabular}

a. Dependent Variable: Kinerja

Karyawan (Y)

Berdasarkan

hasil pengujian pada tabel di atas, diperoleh nilai $\mathrm{t}$ hitung $>\mathrm{t}$ tabel atau $(6,818>1,994)$, dengan demikian hipotesis kedua yang diajukan bahwa terdapat pengaruh yang signifikan atara kepuasan kerja terhadap kinerja karyawan diterima.

Uji Hipotesis Simultan (Uji F) Pengujian hipotesis dengan uji $\mathrm{F}$ digunakan untuk mengetahui hipotesis simultan yang mana yang diterima.

Hipotesis ketiga Terdapat pengaruh yang signifikan antara kompensasi dan kepuasan kerja terhadap kinerja karyawan.

Tabel 11. Hasil Uji Hipotesis Kompensasi dan Kepuasan Kerja Terhadap Kinerja Karyawan

ANOVA $^{a}$

\begin{tabular}{|c|c|c|c|c|c|c|}
\hline \multicolumn{2}{|c|}{ Model } & Sum of Squares & df & Mean Square & $\mathrm{F}$ & Sig. \\
\hline \multirow[t]{3}{*}{1} & Regression & 487.415 & 2 & 243.708 & 35.913 & $.000^{\mathrm{b}}$ \\
\hline & Residual & 475.023 & 70 & 6.786 & & \\
\hline & Total & 962.438 & 72 & & & \\
\hline
\end{tabular}

a. Dependent Variable: Kinerja Karyawan (Y)

b. Predictors: (Constant), Kepuasan Kerja (X2), Kompensasi (X1) 
Berdasarkan hasil pengujian pada tabel di atas, diperoleh nilai $\mathrm{F}$ hitung $>\mathrm{F}$ tabel atau $(35,913>2,740)$, dengan demikian hipotesis ketiga yang diajukan bahwa terdapat pengaruh yang signifikan atara kompensasi dan kepuasan kerja terhadap kinerja karyawan diterima.

PEMBAHASAN

\section{PENELITIAN}

\section{Pengaruh} Terhadap Kinerja Karyawan

Kompensasi berpengaruh signifikan terhadap kinerja karyawan dengan korelasi sebesar 0,615 atau memiliki hubungan yang kuat dengan kontribusi pengaruh sebesar $37,8 \%$. Pengujian hipotesis diperoleh nilai t hitung > t tabel atau (6,573 > 1,994). Dengan demikian hipotesis pertama yang diajukan bahwa terdapat berpengaruh signifikan antara kompensasi terhadap kinerja karyawan diterima.

2. Pengaruh Kepuasan Kerja Terhadap Kinerja Karyawan

Kepuasan kerja berpengaruh signifikan terhadap kinerja karyawan dengan korelasi sebesar 0,629 atau memiliki hubungan yang kuat dengan kontribusi pengaruh sebesar $39,6 \%$. Pengujian hipotesis diperoleh nilai t hitung > t tabel atau $(6,818>$ $1,994)$. Dengan demikian hipotesis kedua yang diajukan bahwa terdapat berpengaruh signifikan antara kepuasan kerja terhadap kinerja karyawan diterima.
3. Pengaruh Kompensasi dan Kepuasan Kerja Terhadap Kinerja Karyawan

Kompensasi dan kepuasan kerja berpengaruh signifikan terhadap kinerja karyawan dengan diperoleh persamaan regresi $\mathrm{Y}=$ $12,025+0,365 \mathrm{X} 1+0,344 \mathrm{X} 2$, nilai korelasi sebesar 0,712 atau memiliki hubungan yang kuat dengan kontribusi pengaruh sebesar $50,6 \%$ sedangkan sisanya sebesar 49,4\% dipengaruhi faktor lain. Pengujian hipotesis diperoleh nilai $\mathrm{F}$ hitung $>\mathrm{F}$ tabel atau $(35,913>2,740)$. Dengan demikian hipotesis ketiga yang diajukan bahwa terdapat berpengaruh signifikan antara kompensasi dan kepuasan kerja terhadap kinerja karyawan diterima.

\section{KESIMPULAN DAN SARAN}

\section{A. Kesimpulan}

1. Kompensasi berpengaruh signifikan terhadap kinerja karyawan dengan kontribusi pengaruh sebesar $37,8 \%$. Uji hipotesis diperoleh nilai thitung $>\mathrm{t}$ tabel atau $(6,573>1,994)$.

2. Kepuasan kerja berpengaruh signifikan terhadap kinerja karyawan dengan kontribusi pengaruh sebesar $39,6 \%$. Uji hipotesis diperoleh nilai t hitung $>$ t tabel atau $(6,818>1,994)$.

3. Kompensasi dan kepuasan kerja berpengaruh signifikan terhadap kinerja karyawan dengan kontribusi pengaruh sebesar $50,6 \%$ sedangkan sisanya sebesar $49,4 \%$ dipengaruhi faktor lain. Uji hipotesis diperoleh nilai $\mathrm{F}$ hitung > F tabel atau $(35,913>$ 
2,740).

\section{B. Saran}

1. Perusahaan harus mengevaluasi kompensasi yang selama ini diberikan kepada karyawan baik menyangkut besarnya gaji, intensif dan tunjangan lainnya.

2. Perusahaan harus mengapresiasi karyawan yang memiliki prestasi agar kepuasan kerja dapat meningkat

3. Kinerja perusahaan dapat ditingkatkan dengan memberdayakan karyawan dengan menegakkan peraturan yang baik dan pemberian kepuasan kerja yang lebih inten lagi.

\section{DAFTAR PUSTAKA}

Algifari. (2015). "Analisis Regresi untuk Bisnis dan Ekonomi". Yogyakarta: BPFE.

Edi Sutrisno (2016). Manajemen Sumber Daya Manusia. Jakarta: Prenadamedia Group.

Gerry Dessler (2016) Human Resources Management, Prenticehall, London: International Inc.

Hasibuan, Malayu S.P. (2016). Manajemen Sumber Daya Manusia. Edisi Revisi. Jakarta: PT Bumi Aksara.

Istijanto (2014) "Riset Sumber Daya Manusia”. Jakarta: PT. Gramedia Pustaka

Mangkunegara, Prabu Anwar. (2016). Evaluasi Kinerja SDM. Cetakan ke tujuh, PT Refika Aditama: Bandung.

Rialmi, Z., \& Morsen, M. (2020). Pengaruh Komunikasi Terhadap Kinerja Karyawan PT
Utama Metal Abadi. JENIUS, 3(2), 221-227.

Rialmi, Z. (2017). Pengaruh Keadilan Prosedural Yang Diterapkan Kepemimpinan Pegawai Dan Kepuasan Kerja Pegawai Terhadap Kinerja Dari Pegawai BPBD Provinsi Riau. Jurnal Mandiri: Ilmu Pengetahuan, Seni, dan Teknologi, 1(2), 353374.Rivai Veithzal (2015) Manajemen Sumber Daya Manusia Untuk Perusahaan. Jakarta: PT Raja Grafindo Persada.

Santoso, Singgih (2015). "Menguasai Statistik Multivariat”. Jakarta: PT Elex Media Komputindo.

Sudjana (2014) "Metode Statistika", Bandung: Tarsido.

Sugiyono (2017), "Metode

Penelitian Administrasi : dilengkapi dengan Metode $R$ \& D". Bandung: Alfabeta.

Roswendi, A. S., \& Sunarsi, D. (2020). Dinamika dan Perkembangan Hypnotherapy Dalam Perspektif Interdisipliner. Cilegon: Runzune Sapta Konsultan

Sunarsi, D. (2019). Seminar Sumber Daya Manusia. Tangerang Selatan: Unpam Press

Sunarsi, D. (2018). Buku Ajar: Seminar Perencanaan Sumber Daya Manusia. Tangerang Selatan: Asmoro Mediatama

Sunarsi, D. (2019). The Analysis of The Work Environmental and Organizational Cultural Impact on The Performance and Implication of The Work Satisfaction. Jurnal Ilmiah Ilmu Administrasi Publik, 9(2), 113122. 


\section{PANDUAN SINGKAT BAGI PENULIS JURNAL SDM JENIUS}

Panduan penulisan ini dimaksudkan untuk menyeragamkan bentuk penulisan karya ilmiah yang dikirim penulis ke redaksi Jurnal Jenius, dengan panduan penulisan sebagai berikut :

1. Naskah ditulis dalam Bahasa Indonesia dengan Abstrak Bahasa Indonesia dalam bentuk Font 12" dengan ukuran 1 Spasi dengan intisari tidak lebih dari 250 kata disertai 3 atau 4 kata kunci (keyword).

Naskah berupa Softcopy program MS Word maksimal 25 Halaman termasuk tabel dan gambar, spasi 1.

2. Sistematika penulisan disusun dengan urutan sebagai berikut :

a) Judul, nama dan alamat email penulis/peneliti tunggal.

b) Abstrak dan intisari, keyword dan kata kunci, dibuat dengan 1 kolom.

c) Batang Tubuh :

1). Pendahuluan, termasuk didalamnya intisari permasalahan

2). Perumusan Masalah

3). Tujuan Penelitian

4). Landasan teori termasuk didalamnya hipotesis dan kerangka Pemikiran

5). Metode Penelitian

6). Hasil dan Pembahasan

7). Kesimpulan

8). Daftar Pustaka

9). Seluruh isi tersebut di buat dengan 2 kolom

3. Judul ditulis dalam bentuk font Times New Roman 12" dengan huruf besar kecil dicetak tebal dan ditempatkan ditengah halaman,, serta tidak lebih dari 18 kata.

4. Tulisan karya ilmiah dalam bentuk font Times New Roman 12" dengan ukuran spasi 1,0 spasi dalam bentuk kolom.

5. Gambar diberi nomor dan keterangan, sedangkan tabel diberi nomor dan keterangan diatasnya.

6. Penulisan persamaan matematika yang terdapat pada halaman naskah hendaknya menggunakan equation editor.

7. Daftar pustaka hanya memuat literature yang dirujuk dalam keterangan dan dicantumkan pada bagian akhir naskah dilakukan dengan memberikan nomor.

8. Margin atas dan kiri $4 \mathrm{~cm}$, kanan dan bawah $3 \mathrm{~cm}$, dan ukuran kertas A4.

9. Email Redaksi : jurnalsdm.unpam@gmail.com/denoksunarsi@gmail.com. 